\title{
UTILIZING BIG DATA IN INDUSTRY 4.0: MANAGING COMPETITIVE ADVANTAGES AND BUSINESS ETHICS
}

\author{
Mohammed Ali Berawi ${ }^{1 *}$ \\ ${ }^{1}$ Faculty of Engineering, Universitas Indonesia, Kampus UI Depok, Depok 16424, Indonesia
}

Industry 4.0 has arisen from an advancement of information and data technology. Thus, data has becomes valuable knowledge that can be organized, managed, and utilized to enhance productivity performance and further innovation in order to gain more competitive advantages for organizations.

Technologies - among others, big data techniques such as machine learning, data mining, crowdsourcing, and time-frequency analysis, etc.- - have been invented to draw useful information that helps organizations gain valuable insights into past and current market behavior in order to predict its future needs and direction by producing innovative business models, projects, products, or services. Harnessing big data in the private and public sectors produces enormous benefits. The utilization of big data has been used to reduce production cost and working capital and to further increase productivity, improve quality, and generate more business revenues for both sectors. As a result, information is more usable and accessible for both service providers and customers, and therefore, resulting in value creation and competitive advantages.

However, some challenges on managing data and information are existed, mainly regarding privacy protection and data security. Collecting, managing, and utilizing the data can be a problem if not performed with the proper mechanism and authorization.

\section{Data Protection, Privacy, \& Security}

Competition around new business models should be designed to enable data utilization to enhance industrial applications that are beneficial for end users. Companies bear a high degree of responsibility, including data confidentiality protection. Data privacy breakdowns and the use of private information for inappropriate and harmful purposes can be destructive for business reputations.

Blown away by digital world freedom, people have detailed their personal data, interests, even obsessions on social media platforms, generating a river of data that can be collected and harnessed for advertising or other means. We live in a world full of tangible and intangible data, where some people may gain benefits from others' personal information with few constraints and almost no supervision. Furthermore, some individuals or organizations have taken advantage of social and digital platforms to deceive, mislead, or harm others by creating or disseminating fake news and disinformation. Thus, with such economic value, data is now too valuable to go unregulated. For example, the current scandal involving Cambridge Analytica exposes how we need a better data-protection system.

Well aware of this situation, the European Union has exhibited a fast breakthrough response toward the rising threat of data misuse through the issuance of the General Data Protection Regulation that will enter into force next month. Businesses that neglect to consider and implement privacy requirements and data protection will be subject to enforcement actions. As a result, failure to comply with the regulation is subject to a fine up to either $4 \%$ of an organization's global turnover or EUR 20 million for noncompliance. Furthermore, utilizing algorithms and

\footnotetext{
*Corresponding author's email: maberawi@eng.ui.ac.id, Tel. +62-21-7270029, Fax.+62-21-7270028

Permalink/DOI: https://doi.org/10.14716/ijtech.v9i3.1948
} 
crowdsourcing technologies, strengthening online accountability, and performing peer-to-peer review as well as improving public digital literacy can be optimized to mitigate data misuse and disinformation.

The organizations must set up their own governance systems to ensure adherence of data protection toward the highest level of integrity and business ethics. Data privacy policies should be integrated into mainstream business; thus, all protected data must correctly be identified, handled, transmitted, and utilized.

\section{Enhancing Technology Performance}

Technology has been used to improve performance and usefulness of projects, products, or services. In this edition, we are pleased to present twenty selected papers dedicated to technology improvement in project, product, and service design. The papers consist of various studies that contribute to improving end-result performance.

The first paper, written by B. Olufemi and O. Eniodunmo, investigates the comparative adsorptive removal of $\mathrm{Ni}$ (II) ions from an aqueous solution using coconut shell and banana peel. The authors argue that the optimum conditions obtained for both adsorbents were $4.5 \mathrm{~g}$ adsorbent dose, $30 \mathrm{~min}$ contact time, and $25^{\circ} \mathrm{C}$ for coconut shell and $4.5 \mathrm{~g}$ adsorbent dose, 120 min, and $25^{\circ} \mathrm{C}$ for banana peel.

The next paper, written by M. Khalil, N. Liu, and R. Lee, investigates the synthesis and electro deposition of iridium oxide nanoparticles to fabricate an Au-based super-Nernstian potentiometric $\mathrm{pH}$ sensor. The authors argue that the as-prepared sensor exhibited excellent $\mathrm{pH}$ sensitivity and good stability over a long period, with a super-Nernstian response value of $-73.7 \mathrm{mV} / \mathrm{pH}$.

The third paper, written by D. Handayani, R. Amalia, M.E. Yulianto, I. Hartati, and Murni, proposes an alternative ginger oil production process by enzymatic extraction using cow rumen enzymes. The authors argue that the extraction with a rumen ratio of $1: 5$ at $60^{\circ} \mathrm{C}$ in 5 days produces ginger oil with zingiberene contents of $21.56 \%$ and $26.28 \%$ at $\mathrm{pH} 5$ and $\mathrm{pH} 4$, respectively.

The fourth paper, written by H. Kristianto, S. Paulina, and J.N.M. Soetedjo, examines the utilization of Moringa oleifera, Carica papaya, and Leucaena leucocephala seeds as natural coagulants for synthetic turbid water. Based on the fourier transform infrared (FTIR) study, the authors argue that all the seeds contained active coagulant agents and could be used to treat turbid water.

The fifth paper, written by A. Haris, B.S. Murdianto, R. Sutatyo, and A. Riyanto, presents a geological model using the artificial neural network (ANN) approach with vertical and lateral distribution that represents the framework of the geological change of sonic log properties. The authors argue that the pseudosonic log shows good agreement with the real sonic log data, which are represented by a correlation coefficient of 0.91 .

The next paper, written by A. Wibowo and K.O. Salleh, investigates land cover types and their effect on urban heat signature (UHS) using remote sensing. Based on the selected case studies, the authors argue that UHS behavior is an effect of the temporal relation of land cover on the localized urban environments.

The seventh paper, written by H.F. Sundoko, R. Akbar, D. Zulkaidi, and T.A. Argo, investigates the perception of terror risk and of the security of counter-terrorism design in public spaces. The authors argue that the best practical implementation to enhance the perception of security and to secure public spaces can be made by combining physical and organizational approaches. 
The eighth paper, written by S. N. Kamaruzzaman, A. Razali, E.M.A. Zawawi, S.A. Basir, and M. Riley, examines residents' satisfaction toward the indoor environmental quality (IEQ) of a re-engineered affordable housing scheme. The authors investigate the residents' dissatisfaction level toward IEQ factors, such as noise, glare, and privacy, and the aspects of the IEQ that are important, such as ventilation.

The next paper, written by C.N.N. Karina, A. Awaludin, B. Suhendro, and P. Chun, investigates the collapse mechanism of the Aтmu Hawu Traditional House, which uses palm wood (Borassus flabellifer) as the main material and employs the Wallstat program and the extended distinct element method. The authors argue that models reinforced with diagonal bracings are far more effective in the collapse prevention method for the Ammu Наwu house compared to shear walls reinforcement.

The tenth paper, written by S. Janani and A.S. Santhi, examines the behavior of concrete toward impact resistance and mechanical properties by adding hooked-end steel fibers. The authors argue that the proposed multiple linear regression model is able to predict the concrete strengths with a deviation less than $5 \%$ compared to experimental results.

The eleventh paper, written by N. Yadav, S. V. Deo, and G.D. Ramtekkar, presents the results of high-range replacement of normal aggregates with recycled aggregates (RA) from construction and demolition waste for producing sustainable and durable concrete. The authors argue that water diffusion in concrete with RA decreases shrinkage and micro-cracks development; increases hydration and compressive strength; and improves durability indexes.

The next paper, written by H.Z. Rahman, M.A. Berawi, B. Susantono, P. Miraj, J.S. Petroceany, and R. Maya, proposes an alternative contract agreement between the government and business entities in the operation and maintenance phase of railways. The authors argue that five components should be considered when developing an operation and management contract: tariff, risk, feasibility, subsidy, and period of the contract.

The thirteenth paper, written by D.M.P. Wedagama and D. Wishart, investigates the relationship between driver behavior and traffic crashes reported by drivers transporting goods and freight. The authors argue that normlessness consisting of behaviors such as taking a slight risk when overtaking and ignoring speed limits are the most common forms of unsafe behaviors.

The fourteenth paper, written by E. Anggraheni, D. Sutjiningsih, I. Emmanuel, and H. Andrieu, evaluates the role of spatial rainfall variability on watershed response based on weather radar data. The authors argue that the difference in peak discharge, peak time, and the values of the horizontal and vertical gab are effective criteria for quantifying the influence of spatial rainfall variability on the hydrological modeling.

The next paper, written by R. Govindaraju, I.N.K. Dwipayana, and S.Y. Salamah, evaluates the impact of information and technology (IT) governance on the routine operation and enhancement effectiveness in the enterprise resource planning post-implementation phase. The authors argue that IT-business alignment has an impact on the effectiveness of routine operation by fulfilling four indicators of routine operation effectiveness.

The sixteenth paper, written by C. Apriono, A.P. Aji, T. Wahyudi, F.Y. Zulkifli, and E.T. Rahardjo, proposes the design of a high-gain and high-efficiency planar bow-tie antenna for applications using THz frequencies. The authors argue that the proposed design has shown high radiation performance suitable for high-speed transmission systems.

The next paper, written by A. Arief, M.B. Nappu, and Antamil, presents an analytical methodology to determine the placement of reactive power devices in power systems. The 
authors argue that the proposed method can provide a solution for the ideal shunt compensator placement by improving the system's voltage stability and by minimizing losses.

The eighteenth paper, written by C. Hudaya, R. Gunawan, R. Setiabudy, and W. Handini, presents a strategy for minimizing torque ripple in a radial flux inset permanent magnet generator by using a geometric modification of the magnet poles. The authors found that the edge rounding of magnet poles significantly lowered the torque ripple of the generator with a reduction of about $74 \%$ (torque ripple of $7.76 \%$ ).

The nineteenth paper, written by A. Anawati, H. Asoh, and S. Ono, examines the degradation behavior of coatings formed by the plasma electrolytic oxidation technique on AZ61 magnesium alloys containing 0,1 , and $2 \mathrm{wt} \% \mathrm{Ca}$. The authors argue that the corrosion mechanism involved initiating the thinning and penetration of the coating by the electrolyte, which led to the formation of a corrosion pouch at the metal-coating interface.

The last paper, written by A. Protasov, investigates the possibilities of the thermal method for honeycomb panel inspection using three-dimensional computer simulation. The author argues that optimal testing time is significantly different for various types of panels, and the method improves the accuracy of monitoring the honeycomb panels.

I hope that this edition of IJTech conveys some new insights into the way we conduct our research. I am pleased to accept and respond to any comment or enquiry you may have on the direction and content of IJTech, and I invite you to join us in this venture by sending your work for consideration.

With warmest regards from Jakarta,

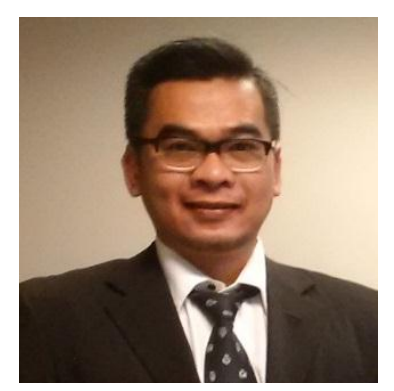

Dr. Mohammed Ali Berawi

Editor in Chief 